\title{
An Assessment of Climate Change Impacts on Streamflows in the Musi Catchment, India
}

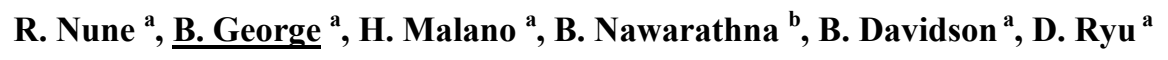 \\ ${ }^{a}$ Department of Infrastructure Engineering, The University of Melbourne, Victoria, 3010 \\ ${ }^{b}$ Department of Climate and Water, The Bureau of Meteorology, Australia \\ Email: biju@unimelb.edu.au
}

\begin{abstract}
The long-term impacts of climate change on water resources are expected to be considerable in Southern India especially in the semi-arid regions. The effects of the changes on precipitation and temperature are expected to alter the hydrology of catchments and ultimately water security. A complicating factor in dealing with climate change from a water resource management perspective in India is the current government policies that promote watershed development (WSD), a policy that promotes the capture of runoff to increase groundwater recharge and irrigation development. In this paper the aim is to quantify the impacts climate change and WSD will have on the hydrologic behavior of the Musi catchment Andhra Pradesh.
\end{abstract}

Global Climate Model (GCM) predictions of future climate are too coarse for hydrological modelling and fail to account for the most important influence on the monsoon rainfall patterns over India. In order to increase the spatial resolution of the models, a dynamic downscaling approach was used in this research. Three climate simulations corresponding to the IPCC-SRES A1B scenario were downscaled for the period 19612098 using "Providing REgional Climates for Impact Studies" (PRECIS) regional climate modelling system. These simulations were based on three versions of the HadCM3 global climate model that showed realistic results for the Indian summer monsoon.

The hydrology of the catchment was modelled using the SWAT hydrologic model. The model was set up for the entire Musi catchment in the Krishna Basin for which the model calibration and validation was carried out at the Osman Sagar and Himayat Sagar gauging stations. Monthly and annual inflows were used to carry out the model calibration. The model calibration and validation yielded Nash-Sutcliffe coefficients ranging between 0.65 and 0.75 , which indicate a good model performance.

The downscaled climate data was then used as forcing data in the model to carry out simulations for all three versions of the climate projection data ((Q0, Q1 and Q14). An analysis of flows at different time slices shows that stream flows decline in the near future (2011-40) and then an increasing trend towards the end of the century. Under the $\mathrm{Q}_{1}$ scenario, annual stream flows show a systematic decline over the period of analysis. The $\mathrm{Q}_{14}$ scenario shows an increase in stream flows over the next few decades followed by a decline towards the end of the century. Potential evapotranspiration is predicted to increase for all the climate scenarios. The reservoir component option available in SWAT was used to assess the impact of watershed development structures in the catchment and the analysis shows that stream flows have been declining due to the growth and impact of these structures in the catchment.

Keywords: Climate Change, hydrology, watershed development 


\section{INTRODUCTION}

Rising amount of greenhouse gas $(\mathrm{GHG})$ in the atmosphere as a result of human activities can alter radiative balances and it may lead to changes in climate variables like temperature and rainfall (Kumar et al, 2006). Such changes in precipitation and temperature are expected to alter local hydrological conditions and may result in large changes in runoff.

Global climate models (GCM's) are generally used to evaluate the impact of increasing GHG concentrations on climate. GCM's generally provide a good representation of the planetary scale features, but their application to regional studies is often limited due to its coarse spatial resolution. Regional Climate Models (RCM's) are developed to dynamically downscale global model simulations to make climate projections for a particular region after superimposing the topographic details of specific regions of interest (Reneesh and Thampi, 2011).

A complicating factor in dealing with climate change from a water resource management perspective in India is the current government policies that promote watershed development (WSD). WSD programs in rain-fed dry land agriculture in India have been introduced to augment surface and groundwater resources by increasing rainwater harvesting. These programs aim to improve the livelihoods of farmers through increased agricultural production in rain-fed areas, and to control droughts by conserving rainwater for use during dry periods. A number of artificial water storage structures like percolation tanks, mini-percolation tanks, check dams, sunken pits, and farm pits have exponentially increased during the last few decades. These changes are expected to increasingly impact river flows although the extent of it is unknown (George et al. 2013).

The main aim in this paper is to quantify the impacts climate change and WSD have on the hydrologic behavior of the Musi catchment.

\section{STUDY AREA AND DATA}

The Musi River, a principle tributary of the Krishna River in India has been selected for this study. The Musi River catchment has a drainage area of approximately $11,000 \mathrm{~km}^{2}$ and supports a population of around 10 million. The climate of the Musi sub-basin is typical of the semi-arid rain-fed conditions found throughout the Deccan Plateau. Summers are hot and winters are temperate.

Musi sub-basin is subject to both South-West and North-East monsoons. The mean annual rainfall of the catchment is $760 \mathrm{~mm}$, is spatially uneven distributed. The land use consists of agriculture, forest, and urban, barren and rocky areas. The major crop in the sub-basin is rice followed by vegetables, groundnuts, cotton, chillies, sugar cane, jowar, bajra, maize and gram.

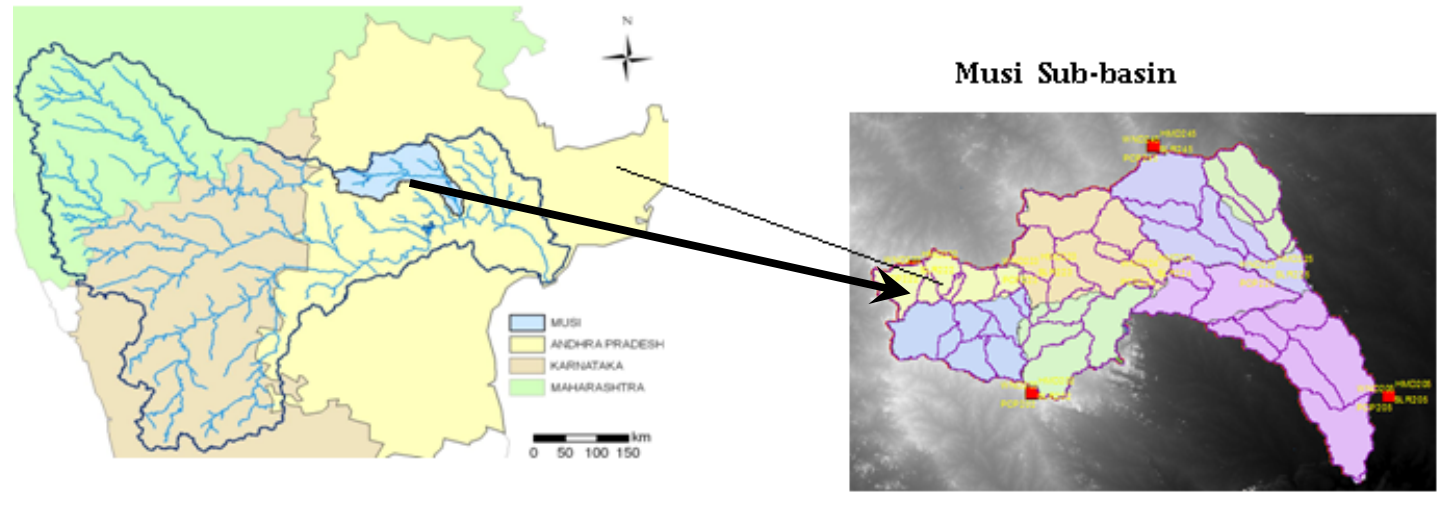

Figure 1. Map of the study area.

The data required for the study were collated from various sources including:

- A land use map of the Musi catchment was prepared using Landsat 2000 satellite imageries. The map consists of nine distinct classes based on land use and irrigation. This map, together with statistical data, is used to estimate crop areas within the basin.

- A 90m spatial resolution Shuttle Radar Topographic Mission (SRTM) Digital Elevation Model. 
- Soil map based on National Bureau of Soil Survey and Land Use Planning classification and soil physical properties were obtained from local publications.

- Climatic data were sourced from the Indian Meteorological Department and the Indian Institute of Tropical Meteorology (IITM).

- The Indian Institute for Tropical Meteorology (IITM) provided PRECIS regional climate model outputs for the period 1960-2098 for A1B IPCC SRES scenarios (Q0, Q1 and Q14 QUMP ensemble).

- Data on hydrological structures (percolation tanks, irrigation tanks, check dams, bunds, farm ponds) collated from Rural Development Department.

- Streamflows at two locations were collated.

- Surveying farmers in the Himayat Sagar catchment provided data on the use of hydrological structures and groundwater for irrigation.

\section{METHODOLOGY}

The water cycle in the Musi catchment, including surface and groundwater resources, is driven by two main forcing variables: climate and watershed development (land use and hydrological structures). The objective of the hydrologic modelling is to assess the impacts of future climate and watershed development changes on the catchment water cycle.

\subsection{SWAT model}

Arc SWAT was used as the hydrological modelling tool for the Musi catchment. It uses an Arc GIS-Arc View extension and has a graphical user input interface to the SWAT model (Arnold et al., 1998, Arnold and Nancy, 2005). The SWAT model is a process-based continuous hydrological model that can be used to assess the impacts of land use and hydrological structures on stream flows. SWAT use spatial variability of land use, soil and climate to capture human induced land and water management practices data in the catchment. The main model components are: climate, hydrology, erosion, plant growth, nutrients, pesticides, land management, channel and reservoir routing.

Surface runoff and infiltration are estimated from daily rainfall using modified SCS-CN (USDA-SCS, 1972) method or the Green-Ampt infiltration and the Muskingum method is used to model channel routing. The model estimates potential evapotranspiration using any of three methods - the Hargreaves method, PriestleyTaylor method and Penman-Monteith method - SWAT simulates plant growth by using a generic crop growth model which first calculates plant growth under optimal conditions, and then computes the actual growth under stresses arising from water, temperature, nitrogen, and phosphorous deficiency.

Data preprocessing in Arc SWAT involves three steps: watershed delineation, a hydrological response unit (HRU) and a weather data definition. The model divides the watershed into sub basins based on the configuration of the stream network. These sub basins are further sub-divided into HRU's, consisting of homogenous land use and soil characteristics. The HRU's represent percentages of the sub basin area and are not identified spatially.

\subsection{Assessing Impact of Climate Change}

Initially, the model was calibrated and validated using historical forcing data (daily rainfall, maximum and minimum air temperature). Rainfall data from 10 precipitation stations were used in the model. Once the model was calibrated and validated, the model was run using the PRECIS climate simulation data covering the period 1960-2098 under three QUMP simulations (Q0, Q1 and Q14). These model outputs were then analyzed and comparisons were made for the periods 1980-2010, 2011-2040, 2041-2070 and 2071-2098.

\subsection{Assessing Impact of Watershed Development}

Man made hydrological structures can be represented in the SWAT model by aggregating them as a reservoir. SWAT can accommodate a single reservoir at the outlet of each a sub basin. The hydrological structures in each sub basin were aggregated into a single structure and the storage area was calculated by aggregating the individual structures. The volume-area relationship estimated using data collated from field 
survey was used to estimate the storage volume. The impact of hydrological structures on streamflow is analysed by running the model with and without any structures and comparing the streamflow in both cases. In this analysis the structure volume was assumed constant throughout the simulation period.

\section{RESULTS \& DISCUSSION}

\subsection{SWAT Model Calibration and Validation}

The SWAT hydrologic model was calibrated using observed inflow data from the two gauging stations in the catchment (Himayat Sagar and Osman Sagar). The calibration procedure involved the manual adjustment of the SWAT parameters such that the resulting streamflows matched the observed inflows at HS and OS reservoir between the period 1979 and 1989 (Garg et al. 2012 and Nune et al. 2011). The model parameters were perturbated based on certain statistical indicators and the field experimental data collected from the study area (Soil parameters like field capacity, wilting point).

The model was subsequently validated using the observed data for the period 1990-1995. This period was selected because it preceded the start of WSD program in India. A sensitive analysis was also carried out to identify and assess the sensitive of model parameters. Based on the sensitivity analysis, the following parameters were identified as sensitive in predicting the streamflows which includes: curve number (CN2), the water holding capacity of the soil, plant uptake compensation factor (Epco), groundwater delay time (Gw_Delay), and surface runoff lag coefficient (Surlag).

The Nash-Sutcliffe coefficient and coefficient of determination were used to evaluate the hydrological goodness of fit were. The result of the model calibration for the HS gauging station is presented in Figures 2. We can observe that the

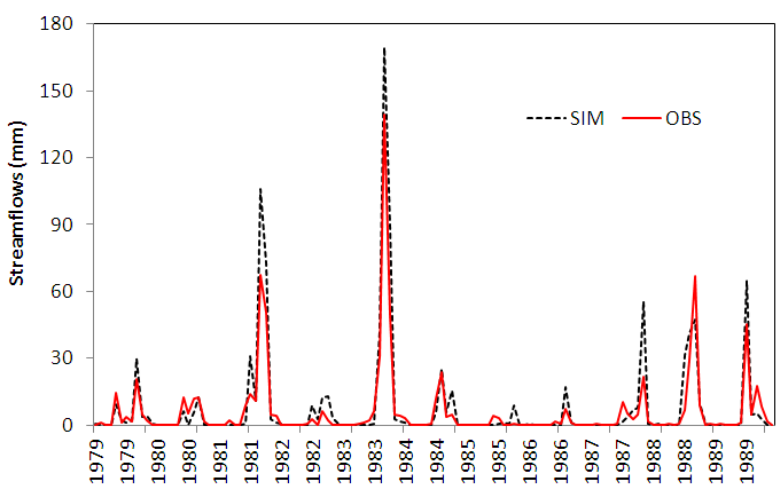

Figure 2. Plots of monthly observed and simulated flows for the calibration period at HS model captures the trends of monthly observed streamflows reasonably well throughout the simulation period. It is observed that the model performs well for the calibration period $\left(1979-1989, E=0.76, R^{2}=0.91\right)$ and validation period $\left(1990-1995, E=0.71, R^{2}=0.75\right)$ for the monthly streamflow comparison (Table 1). The comparison of annual flows resulted in an $\mathrm{R}^{2}$ of 0.96 and 0.91 during the calibration and validation phases.

At Osman Sagar, the Nash Sutcliffe efficiency and coefficient of correlation for monthly flows during calibration period was 0.78 and 0.75 respectively and 0.68 and 0.65 for the validation period, respectively. The comparison of annual flows yielded a coefficient of correlation of 0.82 and 0.94 during the calibration and validation period, respectively.

\subsection{Assessment of Climate Change Impact on Water Resources}

Streamflows were projected into the future using the SWAT model based on the projected rainfall and meteorological data for the $\mathrm{Q}_{0}, \mathrm{Q}_{1}$ and $\mathrm{Q}_{14}$ QUMP climate scenarios generated by the PRECIS model (George et al. 2013).

Table 1. Nash-Sutcliffe coefficient during calibration and validation phases (monthly flows)

\begin{tabular}{|l|c|c|c|}
\hline & Period & $\begin{array}{c}\text { Himayat } \\
\text { Sagar }\end{array}$ & $\begin{array}{c}\text { Osman } \\
\text { Sagar }\end{array}$ \\
\hline Calibration & $1980-1989$ & 0.76 & 0.75 \\
\hline Validation & $1990-1994$ & 0.71 & 0.65 \\
\hline
\end{tabular}

In the $\mathrm{Q}_{0}$ scenario, streamflows show a decreasing trend in the near future and then an increasing trend towards the end of the century for both gauging stations (Osman Sagar and Himayat Sagar). When we compare the average inflow estimated for the entire period 2011-98 in relation to historical flows, it shows an increase of 95\% and 103\% at Osman Sagar and Himayat Sagar, respectively. The streamflow reduction during the period 2011-2040 is estimated at 38\% and 36\% percent respectively for Osman Sagar and 
Himayat Sagar gauging stations (Figure 3). However, we observe a large increase in flows from the middle of the next century onwards for the period 2041-70 and 2071-98 for both stations. At Osman Sagar, the percentage increase in streamflows is estimated at 102 and $123 \%$ from the historical average for the period 2041-70 and 2071-98, respectively. For Himayat Sagar, the increase in streamflows is estimated at $126 \%$ and $125 \%$ from the historical average for the period 2041-70 and 2071-98, respectively. This is mainly due to the predicted increase in rainfall by more than $200 \mathrm{~mm}$ in comparison to the historical average. The comparison of monthly average streamflows for various time slices show that there is a shift in the timing of peak flows from September at present to August in the next few decades. This has significant implications for agriculture in the catchment as more water will be required to meet crop water requirement in those months of reduced precipitation.

Potential evapotranspiration (PET) shows an increasing trend throughout the time slices analysed under the $\mathrm{Q}_{0}$ scenario. The average annual PET was estimated to be $1715 \mathrm{~mm}$ for the historical time series. Average annual PET is expected to increase by $2 \%$ and $5 \%$ for the period $2011-2050$ and 2050 2098 in comparison to the baseline average values. These results indicate that water resources availability will decline in the next few decades while demand will rise, thus requiring adaptation strategies

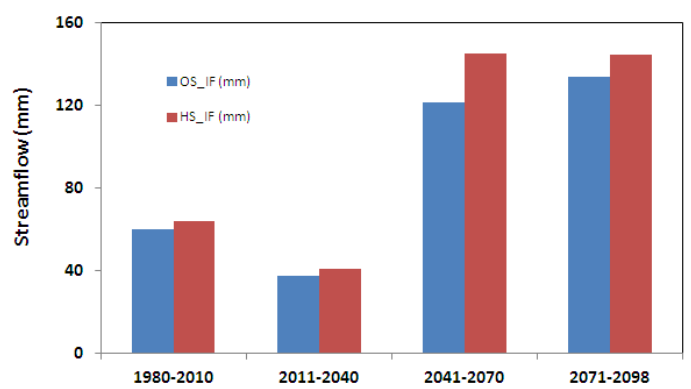

Figure 3. Projected annual streamflow at different time periods- $\mathrm{Q}_{0}$ scenario to cope with this change.

In the $Q_{1}$ scenario, annual streamflow shows a net decline for the entire period 2011-2098 for both gauging stations (Osman Sagar and Himayat Sagar). A comparison of the average inflow estimated for the future (2011-98) with the historical period shows a decrease of $43 \%$ and $63 \%$ at Osman Sagar and Himayat Sagar, respectively. There is a significant flow reduction over the next few decades after 2011 although the trend reverses towards the end of the century. Streamflows show a reduction during the period 2011-2040 estimated at $68 \%$ and $61 \%$ for Osman Sagar and Himayat Sagar, respectively, in comparison to historical averages. The decline in mean streamflows is estimated at $65 \%$ and $80 \%$ from the average historical records for the period 2041-70 at Osman Sagar and Himayat Sagar, respectively; and 10\% and 48\% for the period 2071-2098 for the same stations, respectively. Average PET shows an increasing trend and is estimated to increase by $12 \%$ and $15 \%$ in comparison to current averages in both Osman Sagar and Himayat Sagar.

For the $\mathrm{Q}_{14}$ scenario, future average flows are expected to increase by $46 \%$ and $13 \%$ at Osman Sagar and Himayat Sagar, respectively, in comparison with the historical flows. Streamflows show an increasing trend over the next few decades after 2011 and then decline towards the end of the century. The streamflow increase during the period 2011-2040 is estimated at $60 \%$ and $18 \%$ respectively for Osman Sagar and Himayat Sagar in relation to the historical average. Average PET increases by $2 \%$ and $4 \%$ for the period 2011-2050 and 2051-2098 in comparison to the base period, respectively.

\subsection{Impact of hydrologic structures}

The inflows simulated by the calibrated model with reservoirs (2005 development level) and without reservoirs at sub basin outlets has been analysed for the period from 1995 to 2098 to check the impact of hydrological structures on streamflows using $\mathrm{Q}_{0}$ climate scenario. It is observed that streamflows decline due to the impact of hydrological structures in the catchment. The average annual reduction in streamflows was observed as $13 \%$ in HS (varies from 10 to $19 \%$ ) and $22 \%$ (varies from 10 to $38 \%$ ) in OS (see Table 2). The disaggregated analysis during the wet (Annual rainfall $>850 \mathrm{~mm}$ ), normal (Annual rainfall between $600-850 \mathrm{~mm}$ ) and dry

Table 2. Impact of hydrologic structures

\begin{tabular}{|c|c|c|}
\hline & $\begin{array}{c}\text { \% Streamflow } \\
\text { reduction } \\
\text { Himayat Sagar }\end{array}$ & $\begin{array}{c}\text { \% Streamflow } \\
\text { reduction } \\
\text { Osman Sagar }\end{array}$ \\
\hline $1995-2010$ & -10.25 & -9.27 \\
\hline $2011-2040$ & -19.94 & -38.43 \\
\hline $2041-2070$ & -9.13 & -20.22 \\
\hline $2071-2098$ & -13.64 & -23.02 \\
\hline
\end{tabular}
and $14-80 \%$ respectively. It is evident from the analysis that hydrological structures have an inversely 
proportional effect on streamflows at a catchment scale and this effect is greater than proportional to the rainfall variation due to the large rainfall-runoff elasticity. The analysis also shows that the impact will be most severe during the period from 2041-2070. The large impact during the period 2071-2098 is mainly due to the frequent occurrence of dry years.

\section{DISCUSSION AND CONCLUSIONS}

The semi-distributed hydrologic model SWAT was used to assess the impacts that climate change and WSD have on the behaviour of the surface hydrology in the Musi catchment, India. The model was calibrated using the observed inflow data of the two gauging stations in the catchment (Himayat Sagar and Osman Sagar). The model calibration and validation yielded Nash-Sutcliffe coefficients ranging between 0.65 and 0.75 , which indicate a good model performance. Following calibration and validation, the model was run using the outputs from PRECIS for ensemble members Q0, Q1 and Q14 as forcing variables. The following conclusions can be drawn from the modelling analysis:

- Under the $\mathrm{Q}_{0}$ scenario, the comparison of the future streamflows with the historical flows (baseline) shows a significant net increase of $95 \%$ and $103 \%$ at Osman Sagar and Himayat Sagar, respectively over the period 2011-2098. When we analysed the flows at different time slices, that analysis shows that streamflows decline in the near future (2011-40) and then an increasing trend towards the end of the century.

- Under the $\mathrm{Q}_{1}$ scenario, annual streamflows show a systematic decline over the period 2011-98. A net decrease of $43 \%$ and $63 \%$ is predicted to take place at Osman Sagar and Himayat Sagar, respectively.

- The $\mathrm{Q}_{14}$ scenario shows an increase in streamflows over the next few decades followed by a decline towards the end of the century. On average, streamflows are predicted to increase by $46 \%$ and $13 \%$ in the future in comparison with the historical period at Osman Sagar and Himayat Sagar, respectively

- More importantly, all three scenarios show an increase in flow variability over the entire time series.

- Potential evapotranspiration (PET) is predicted to increase throughout the time slices analysed for all the three climate scenarios. PET was found to be the highest for the Q1 scenario. This would indicate that irrigation water demand will increase in future.

- An assessment of the impact of hydrological structures on streamflows shows that streamflows have been declining due to the growth and impact of these structures in the catchment. The flow decline due to hydrological structures was significant during drought years.

\section{ACKNOWLEDGMENTS}

The authors acknowledge the Australian Centre for International Agricultural Research (ACIAR) for their financial support.

\section{REFERENCES}

Arnold, J.G., Srinivasan R., Muttiah R.S., and Williams J.R., (1998). Large area hydrologic modelling and assessment Part 1: Model development, Journal of the American Water Resources Association 34(1): 73-89.

Arnold, J. G., and Nancy. F. (2005). SWAT2000: current capabilities and research opportunities in applied watershed modelling. Hydrological Processes 19(3): 563-572.

Garg. K., Bharathi. L., Gaur. A., George. B.A., Acharya. S., Jella. K., and Narasimhan. B. (2012). Spatial Mapping of Agricultural Water Productivity using SWAT model in Upper Bhima Catchment, India, Irrigation and Drainage, 61(1): 60-79.

George. B.A., Malano. H.M., and Davidson. B. (2013). Hydrological Modelling of Musi Catchment, ACIAR Annual Report No. 3, ACIAR, Canberra.

Kumar. R, Sahai. A.K., Kumar. K., Patwardhan. S.K., Mishra. P.K., Revdekar. K.G., Kamala.K., and Pant. G B. (2006). High resolution climate change scenarios for India, Current science 90, 3, 334-345. 
Nune. R., George. B.A., and Western. A.W. (2011). An Assessment of the Anthropogenic Impacts on Streamflows in the Himayat Sagar Catchment, India using SWAT, 34th IAHR World Congress - Balance and Uncertainty 1443-1450

Raneesh. K.Y., and Santhosh G.T. (2011). A study of impact of climate change on streamflow at the watershed scale in the humid tropics. Hydrological Sciences, 56(6): 946-965. 